\title{
Encarte digital
}

\section{Sobre o tratamento dado às fronteiras profissionais na assistência aos jovens \\ Uma análise empírica de discussões em grupo}

\author{
Professional praxes in youth welfare services \\ as border-work \\ An empirical analysis of group discussions
}

Birgit Bütow Eva Gries*

\begin{abstract}
Resumo: O texto contém resultados parciais de uma pesquisa qualitativa que examina os processos de legitimação das competências da Pedagogia Social exemplarmente na interface entre a assistência social a crianças e jovens $(\mathrm{KJH})$ e a assistência psiquiátrica a crianças e jovens (KJP) no contexto alemão. A questão central é como a competência profissional da Pedagogia Social e seu conhecimento especializado se articulam, constituem e afirmam. Zonas de tensão e de cooperação são os pontos de referência escolhidos neste contexto e que tomamos como motivo para reconstituir processos e modos de tratamento das fonteiras profissionais. A categoria "tratamento de fronteira", desenvolvida por Susanne Maurer e Fabian Kessl, nos serve como base metodológica. No texto, depois de uma breve inserção teórica, esboçamos, com base em dois exemplos de discussões em grupo, como se constitui a cooperação como processos de tratamento de fronteira. Por fim, esses resultados são discutidos no contexto da pesquisa sobre a profissão da Pedagogia Social.
\end{abstract}

Palavras-chave: Tratamento de fronteiras. Competências e especialidades da Pedagogia Social. Serviço Social. Cooperação interdisciplinar. Método documental.

\footnotetext{
* Birgit Bütow é socióloga e assistente social, livre-docente em Pedagogia Social pela Universidade Técnica de Dresden, professora titular na Faculdade de Ciências da Educação da Universidade de Salzburg (Áustria)<birgit.buetow@sbg.ac.at>. Eva-Maria Gries é professora assistente e pesquisadora na Universidade de Marburg (Alemanha) < griesev@staff. uni-marburg.de>. O texto é resultado parcial do projeto "Legitimação das competências da Pedagogia Social nas zonas de tensão da cooperação: o caso da assistência à juventude e a psiquiatria" financiado pela Deutsche Forschungsgemeinschaft. As autoras agradecem a Iris Gräser, de Marburg, pela leitura crítica e comentários sobre o texto. Tradução do alemão por Emil A. Sobottka.
}

\begin{tabular}{|l|l|l|l|l|l|}
\hline Civitas & Porto Alegre & v. 13 & n. 3 & p. e15-e34 & set.-dez. 2013 \\
\hline
\end{tabular}




\begin{abstract}
Initiated by Susanne Maurer and Fabian Kessl in 2005, the discourse on social work as boundary- or border-work has now been taken up by the profession and scientific discussion proven in initial empirical analyses, and thus been further defined. In this article we will try to line out the analytic potential of this concept, and suggest some further differentiations which are based on the theoretical assumptions and first results from our current DFG research project on the challenges of legitimizing social work competency in areas of cooperative tension. We will approach this in three steps: first, we will summarize some of the theoretical frameworks of our project and try to connect them to boundary-analytic perspectives. Second, we will discuss our first research findings on social work in areas of cooperative tension. Thirdly, in conclusion, we will formulate some poignant thoughts as to gain a more precise theoretical understanding of the analytical potential of boundary-analytical perspectives related to cooperation especially in focus to research social work as a profession by legitimizing. Keywords: Border-work. Expertise and competence of Social Pedagogy. Social Work. Interdisciplinar collaboration. Documentary method.
\end{abstract}

\title{
Introdução
}

A questão central de nosso projeto de pesquisa bem como deste texto é a pergunta pela articulação, constituição, afirmação e legitimação das competências e do conhecimento especializado da Pedagogia Social. A pergunta é relevante para o Serviço Social porque, devido a sua vinculação sistemática com instituições do estado de bem-estar social e sua transformação, suas complexas atribuições na tensão entre assistência e controle, a coprodução com seu público-alvo, seu projeto e sua ética profissionais bem como devido a seus múltiplos enquadramentos institucionais e a suas práticas profissionais concretas, o Serviço Social pode ser designado como "um projeto arriscado e aberto", que necessita certificar-se a si próprio sempre de novo (cf. Bütow e Maurer, 2013). Para dar conta empiricamente desta questão, nós escolhemos e fundamentamos metodologicamente a cooperação entre a assistência social à juventude e a assistência psiquiátrica a jovens como acesso exemplar (Bütow e Maurer, 2011). As razões para esse acesso são diversas: a cooperação entre e dentro de instituições pode ser vista como uma característica essencial da atividade sociopedagógica no âmbito da assistência à juventude. Devido à diferenciação do cenário assistencial, a cooperação passou a ser constitutiva para o Serviço Social (cf. Bauer, 2005; Bommes e Tacke, 2011; Fischer e Kosellek, 2013; Weber, 2005). Com isso o Serviço Social transpõe, pelo menos temporariamente, as fronteiras organizacionais, tornando necessária a negociação sobre e a legitimação das competências profissionais. Nós partimos do pressuposto que nas interfaces interdisciplinares os modelos óbvios e não 
questionados de legitimação das competências profissionais se tornam frágeis e que em consequência as profissões envolvidas são desafiadas a fazer valer seu conhecimento especializado e suas competências. Com isso, os profissionais não são apenas desafiados a se ocuparem com a questão a respeito de onde efetivamente estão seu conhecimento especializado e suas competências assim como seus limites, mas eles também são convocados a ajudar a conformar com sua atuação profissional as transições na "zona" de cooperação. Assim é possível tornar acessíveis de modo exemplar, com base nas "zonas de tensão e de cooperação", os processos de desdobramento, afirmação, articulação e legitimação do conhecimento especializado e das competências para pesquisas empíricas.

No projeto de pesquisa nós nos referimos heuristicamente de um lado aos discursos profissionais das ciências da educação e aos modelos reflexivos sobre a profissão (cf. Dewe e Otto, 2011; Müller, 2012), que tomam como ponto de partida a noção de que as práticas pedagógicas sejam performativas e têm como base um saber e um conhecimento determinados. Por outro lado nós nos baseamos em que essa performatividade está emoldurada em e por organizações e instituições (cf. Bütow e Maurer, 2011). Com os conceitos de "conhecimento especializado" e "competências" nós assinalamos a referência à pesquisa sobre profissões e organizações emoldurada pela fenomenologia e pela análise do poder. Ao mesmo tempo nós focalizamos nossos dois aspectos centrais - competências e conhecimento especializado - no contexto da pesquisa do Serviço Social e da Pedagogia Social sobre profissões: as competências sociopedagógicas, devido a suas especificidades estruturais, não podem ser simplesmente fixadas por decreto, instrução normativa ou mesmo profissionalização, mas se afirmam através de atuações profissionais concretas dentro de organizações - em comparação, em cooperação e através de delimitações face a outras profissões. As organizações do serviço social são consideradas como resultado de processos profissionais e técnicos de interpretação, classificação e atribuições de competências de e em situações problemáticas. A legitimidade das organizações e, com isso, da atuação profissional na tríade de regulação, normatividade e conhecimentos acumulados (cf. Powell, 2009) resulta de adscrições processuais de atores e atoras organizacionais dentro e entre organizações e seus grupos de referência na medida em que seus conteúdos (institucionalizados) são reconhecidos. "Legitimidade significa a adscrição que ocorre no ator que julga e não é primariamente um atributo de instituições. A efetivação de expectativas sociais em estruturas e práticas organizacionais pode produzir legitimidade, mas não necessita fazê-lo obrigatoriamente, uma vez que a legitimidade depende apenas 
da avaliação dos grupos relevantes de referência no ambiente da organização" (Koch, 2009, p. 126). Processos da geração, aplicação e reconhecimento de legitimidade são por conseguinte designados de legitimação.

Enquanto "competência" se refere ao aspecto organizacional e institucional da atuação da Pedagogia Social, "conhecimento especializado" se refere aos pressupostos técnicos (formação, certificados, saber, experiência). O termo "conhecimento especializado" (expertize) é relativamente novo no debate sociopedagógico e, do mesmo modo que "competências", caracteriza tanto a necessidade de processos de legitimação como também a abertura e indeterminação correlatas.

Como nós, tendo como referência pressupostos cognitivos da análise de hegemonia e poder (p. ex. Foucault, Laclau, Mouffe), partimos da convicção de que na modelagem da cooperação são documentados processos de desdobramento, afirmação, articulação e legitimação do conhecimento especializado e das competências do saber sociopedagógico, a questão como o conhecimento específico e a competência da Pedagogia Social se constitui é analisada na interface entre a assistência social a jovens e a assistência psiquiátrica a jovens como uma zona exemplar de tensão cooperativa (cf. Bütow e Maurer, 2011).

O material empírico disponível até agora - em junho de 2013 - e sobre o qual está baseada a análise intermediária aqui apresentada abrange 26 entrevistas com profissionais colaboradores de organizações estatais e nãoestatais de assistência a jovens e de serviços sociais em psiquiatrias para crianças e jovens, sete discussões em grupos focais com colaboradores de organizações de assistência a jovens e quatro observações etnográficas de discussões interdisciplinares de casos. As entrevistas serviram para a análise do conhecimento e da experiência de profissionais como especialistas na interface multiprofissional. Num primeiro passo, as entrevistas foram analisadas de forma qualitativa em seu conteúdo, resultando em retratos descritivos de caso. Num segundo passo esses retratos foram parcialmente analisados com o método da hermenêutica objetiva. As discussões em grupo, com as quais se pretende captar os espaços conjuntivos experimentais em organizações, foram realizadas sempre com equipes de uma mesma organização. Elas ainda estão em avaliação através do método documental de Bohnsack (1993; 1997). O material é contextualizado através de uma análise do enquadramento institucional e social baseado numa análise documental (cf. Bütow e Maurer, 2011).

No presente artigo apresentaremos inicialmente algumas reflexões teóricas de fundo a respeito do tratamento de fronteira na assistência a jovens. 
Para tanto será feita uma contextualização nas discussões atuais das ciências da educação às quais nos referimos. Será desdobrado o modo como tratamos em nosso contexto a imagem do tratamento de fronteira. Ademais será esclarecido qual o papel e significado atribuído ao conceito de cooperação nesta situação. Em seguida serão apresentados, com base em dois exemplos, os modos de tratamento de fronteiras profissionais como primeiros resultados intermediários de nosso projeto de pesquisa. Por fim, discutiremos possíveis resultados, definições e pontos de contato para a pesquisa sobre profissões.

\section{Reflexões sobre o tratamento de fronteira na assistência a jovens com base na cooperação}

\section{Fronteiras e tratamento de fronteira no Serviço Social}

Discussões atuais das ciências sociais a respeito do conceito analítico de "fronteira" são cada vez mais presentes nas ciências da educação e na Pedagogia Social (cf. Müller et al., 2013; Hörster et al., 2013), mas também podem ser encontradas, entre outras, na Sociologia (cf. Fuhse e Mützel, 2010). Os debates sobre fronteiras se ocupam sobretudo de seus efeitos: com a formação de identidade, estruturação de territórios, espaços ou desigualdades sociais ao longo do eixo de dimensões sociais como sexo, idade, classe social ou etnia (cf. Karafillidis, 2010). A inserção relacional em redes e o contexto de surgimento e desenvolvimento com frequência é visto de forma unilateral, normativa ou fixa. Contudo, fronteiras são ao mesmo tempo processuais. Tomando como referência Georg Simmel (1999) é possível assumir como certo que a constituição de diferença pelo estabelecimento de fronteiras e a transgressão de fronteiras são constitutivos para os ordenamentos sociais. Assim, por exemplo, a demarcação de fronteiras serve para que pessoas possam se orientar e possam diminuir inseguranças; por outro lado, com a transgressão de fronteiras se destaca o aspecto do desenvolvimento e da mudança. Isso significa que aparentemente existem fronteiras fixas, normativas - no Serviço Social, por exemplo, através de estruturas consolidadas das competências fixadas em lei -, mas ao mesmo tempo existem transgressões e delimitações. Necessárias se tornam ao mesmo tempo uma determinação, discussão e análise dos atores e de seus "objetos de fronteira” (Hörster et al., 2013) como também uma identificação e reconstrução dos processos ali presentes e das emergentes zonas de fronteira. Como objetos de fronteira podem ser compreendidos pontos comuns de referência entre diferentes contextos sociais ou estruturas no cotidiano, no agir profissional e na ciência (cf. Baader, 2013), que possibilitam a compreensão, a tradução, a transmissão ou outras formas de referência 
recíproca. Eles podem ser encontrados na perspectiva epistemológica, nos campos de atuação profissional (p. ex. no Serviço Social: nos casos ou no debate sobre a definição social de problemas), na cooperação bem como nos já referidos processos de formação de identidade (cf. Hörster et al. 2013).

Mesmo sem poder entrar nos diferentes debates atuais no contexto do Serviço Social como tratamento de fronteira (cf. Heite et al. 2012; Böllert, 2013), pretendemos esboçar brevemente alguns aspectos centrais: o conceito "Serviço Social como tratamento de fronteiras", usado por primeira vez no contexto do Serviço Social em 2005 por Susanne Maurer e Fabian Kessl, tornou-se em brevíssimo tempo uma metáfora popular e ambígua (cf. Bütow, 2012). Ele se refere essencialmente a dois âmbitos: primeiro, às bases de um Serviço Social crítico e, segundo, à análise do agir profissional no espaço da tensão de diferenças sociais. A imagem do Serviço Social como tratamento de fronteira em sua primeira denotação aponta para ambivalências na tensão das funções sociais de normalização e normatização e seus potenciais socialmente críticos. Ela portanto abarca a racionalidade da (re)produção das relações sociais de força e poder (cf. Karafillidis, 2010) -na qual o Serviço Social está enredado e do qual participa- e com isso ao mesmo tempo viabiliza potenciais críticos e reflexivos frente a realidades e estruturas sociais (cf. Kessl e Maurer, 2009). Estas reflexões se referem a três âmbitos: o Serviço Social participa da produção e reprodução de fronteiras, por exemplo no contexto de práticas de normalização, da exclusão, do disciplinamento e da punição. Mas ele é ao mesmo tempo defensor dos seus grupos-alvo ao criticar condições discriminatórias de vida e se empenhar por justiça e participação; ele é aberto com relação a seus objetivos, ele atua abrindo alternativas e é, assim, emancipatório. Segundo, o Serviço Social atua como fronteiriço, como transgressor de fronteiras, quando ele por exemplo cria lugares e possibilidades ali onde o apartado, o conhecido, o normatizado se confrontam, onde o comum e conflituoso vem à luz e pode ser processado. E, terceiro, fronteiras também podem ser deslocadas ou mesmo suspensas no sentido de ampliar possibilidades e competências alternativas. Por isso, com essa imagem é possível captar teoricamente tanto a produtividade do social como também fundamentar metodologicamente a análise empírica de práticas (profissionais ou mesmo organizacionais) de tratamento de fronteira (cf. Bütow, 2012a; Kessl e Maurer, 2009). No presente texto nós queremos nos concentrar sobre esse último aspecto no sentido da transposição e da demarcação de fronteiras relativas à competência e ao conhecimento especializado (de profissões e organizações), sem desconsiderar que todos os aspectos citados acima são interdependentes. Com as descrições feitas acima, fronteiras e tratamento de 
fronteiras escapam de qualquer fixação ou definição; antes, tratam-se aqui de imagens metodológicas da análise de processos complexos, como já foi indicado com relação a articulação, desdobramento afirmação e legitimação do Serviço Social e será ainda mais diferenciado e concretizado no que segue. ${ }^{1}$

\section{Tratamento de fronteira e cooperação como "objeto de fronteira"}

Este texto enfoca as práticas de tratamento das fronteiras profissionais com base na cooperação na assistência a jovens. As "zonas" de cooperação são significativas para nós como "objetos de fronteira" porque os participantes da cooperação se referem a eles, mas os dotam cada um com sentido específico e os conformam de modos distintos com seu trabalho prático. A cooperação nos serve como ponto de referência. Partindo dela, nossa questão central será voltada aos processos de legitimação das competências e do conhecimento especializado da Pedagogia Social.

A cooperação pressupõe que pelo menos duas unidades participem dela, e que estejam ligadas através de uma terceira, comum. Nesse sentido, a transgressão da fronteira é inerente à cooperação. E ao revés: uma transgressão da fronteira das próprias competências profissionais e do conhecimento especializado exige a cooperação com outras profissões (cf. Vogd, 2009).

Dentro do marco de nossa questão e em comparação com estudos empíricos atuais nas ciências da educação sobre cooperação (cf. Düring, 2011; Vogd, 2009), não tratamos de analisar o acontecimento da cooperação em si, aprofundar a definição do conceito de cooperação ou perguntar pelas condições para uma cooperação bem sucedida. Em nosso contexto, a cooperação serve antes como "objeto de fronteira", que constitui um ponto comum de referência: através de áreas de interface nos destinatários e em suas situações problemáticas assim como na legislação sobre a assistência à criança e ao jovem. Com base nesse ponto de referência será tratada a questão como as fronteiras profissionais são tratadas pelos serviços de assistência aos jovens.

A interface entre a assistência social ao jovem (KJH) e a assistência psiquiátrica a jovens (KJP) pode ser considerada como uma fronteira na qual dois sistemas independentes de assistência se defrontam. A assistência social ao jovem e a assistência psiquiátrica a jovens pertencem a disciplinas distintas. Elas se diferenciam, entre outras, pelas estruturas concepcionais e do agir,

Não serão expostas, mas pressupostas as discussões sobre a deslimitação do Serviço Social no contexto dos debates sobre a educação ampliada (Böllert, 2013). 
pela autocompreensão, atribuições e objetivos, organizações, financiamento, reconhecimento social, hierarquia e poder de definição. Ao mesmo tempo elas estão vinculadas uma a outra através de um terceiro, que torna a cooperação necessária. Devido à definição ampla das áreas de atribuição, os grupos-alvo comuns pertencem a esses vínculos: o grupo das crianças e dos jovens em geral, assim como uma criança ou jovem em particular. Ademais, fazem parte destas vinculações âmbitos comuns de responsabilidade, como por exemplo, segundo o §35 da Lei Alemã de Seguridade Social, que regulamenta a assistência integradora de crianças e jovens com deficiência mental ou ameaçados dessa deficiência. Dessa vinculação resulta que destinatários dos dois sistemas de assistência podem ter a mesma constelação de problemas e que a mesma pessoa pode ser destinatária simultaneamente dos dois sistemas (cf. Wehner, 2002; Fegert e Schrapper, 2004; du Bois e Die-Schwarz, 2011). Contudo, a modelagem da cooperação é determinada pelo agir dos profissionais em suas próprias organizações respectivas (cf. Bütow, 2012a; 2012b). Tal como já foi referido, a profissionalidade da Pedagogia Social pode ser descrita como dupla e ambivalente: por um lado a Pedagogia Social é responsável e relacionada a âmbitos concretos de atuação e a tarefas específicas, por outro lado, por sua competência geral, ela tem um campo aberto de atuação. $\mathrm{Na}$ atuação pedagógica, que via de regra ocorre no agir conjunto com outras instituições ou organizações, a competência e o saber especializado da Pedagogia Social precisa afirmar-se, por exemplo com relação à definição de problemas e ao desenvolvimento de medidas cabíveis (cf. Düring, 2011). Com isso se coloca a questão sobre como a zona de fronteira entre a assistência social e a assistência psiquiátrica a jovens é tratada e modelada pelos profissionais da assistência social a jovens.

\section{Modos do tratamento de fronteira - exemplos do material empírico}

No que segue apresentamos os resultados intermediários de dois grupos de discussão com profissionais de duas organizações de assistência estacionária a jovens, para permitir uma visão do uso empírico da imagem do tratamento de fronteira já apresentada. Para isso escolhemos duas breves passagens em cada caso: uma passagem que envolve reações à pergunta introdutória e uma passagem na qual é discutida a relação com a assistência psiquiátrica a jovens. ${ }^{2}$

2 N.T. Sobre essa técnica de trabalho com entrevistas, ver o texto de Wivian Weller (A contribuição de Karl Mannheim para a pesquisa qualitativa: aspectos teóricos e metodológicos. Sociologias, v. 7, n. 13, p. 260-300, 2005). Os códigos de transcrição estão explicados no anexo 2. Agradeço a Hermílio Santos pela indicação desse texto. 
Grupo "Montanha" 1. 8-31

Y1: [ relação à cooperação entre colegas?

] Que experiências vocês têm com

P1: Com a psiquiatria?

P8:

Y1: Hm.

I_ Na organização?

P8: Então é o seguinte: quando colegas na organização? (Não)

Y1: a que ponto querem dar importância.

I_ Vocês mesmos escolhem P10: internos aqui ou também a, eh Ah bom. Pode se referir a, a procedimentos Y1: Hm. Exato. Exato. Hm.

P8: I_Ah bom.

P10: fundo] Bem.

Okay. [respira

P11+P10: 1_@

Grupo "Ponte" 1. 7-27

Y1: [ com a cooperação entre colegas?

] eh, que experiências vocês têm

P5: (5) A pergunta se refere a que âmbito, entre os psiquiátricos e nós pedagógicos?

Y1: I_ Isso por assim dizer vocês decidem,

P5: $\mathrm{Hm}$

Y1: a qual (.) âmbito vocês querem (eh) se referir (.) agora.

P5: Ou também entre nós?

Y1: Sim, exato.

P5: Também, também

Y1:

I_ Também entre vocês hm

P5: Okay.

Ao estímulo inicial, ${ }^{3}$ que perguntava sobre experiências com a cooperação entre colegas, segue-se nos grupos "Montanha" e "Ponte" uma fase de esclarecimento do tema. Com o objetivo de chegar a uma delimitação do tema são feitas perguntas de esclarecimento a Y1. Por conseguinte torna-se

3 O estímulo inicial era: "Nós os entrevistamos individualmente no diálogo com especialistas a respeito da interface da assistência social a crianças e jovens $(\mathrm{KJH})$ com a assistência psiquiátrica a jovens (KJP). Hoje queremos nos reunir num círculo ampliado. Gostaria de fazer a pergunta: quais experiências vocês têm com relação à cooperação entre colegas?" A abertura e indeterminação da pergunta contrasta com o conhecimento anterior dos participantes, de que o interesse de pesquisa se refere sobretudo à interface entre a assistência social a jovens e a assistência psiquiátrica a jovens. Através dessa indeterminação, nosso objetivo aqui era conscientemente o de provocar uma certa irritação, que permite um novo posicionamento em relação ao desenvolvimento do tema e, com isso, o desdobramento de novos marcos de referência. 
necessária uma negociação e sintonização comunicativa do tema da discussão em grupo. Nisso se revela uma irritação que pode ser devido a que a abertura e indeterminação da pergunta inicial não coincide com o conhecimento prévio sobre os objetivos da pesquisa e com as expectativas dos participantes. Eles sabiam que o projeto de pesquisa está voltado à questão da cooperação com a assistência psiquiátrica a jovens. A abertura temática da pergunta inicial em direção a experiências na cooperação entre colegas sem uma referência explícita à assistência psiquiátrica a jovens desencadeia inicialmente uma irritação em ambos os grupos e convoca os participantes a se orientarem com relação ao marco de referência da cooperação entre colegas.

Nos dois grupos as perguntas subsequentes têm como objetivo uma delimitação do tema que deve esclarecer se a discussão deve tematizar a cooperação interna ou externa. Enquanto no grupo "Ponte" essa tentativa de esclarecimento é feita por uma pessoa, no grupo "Montanha" isso ocorre na forma de divisão do trabalho. Nisso ficam evidenciadas culturas comunicativas distintas ou culturas distintas relativas à divisão de trabalho nas duas organizações. Na sequência o grupo "Montanha" enfoca então primeiro os procedimentos internos na passagem da organização de assistência social a jovens para a assistência psiquiátrica a jovens, enquanto o grupo "Ponte" se refere à cooperação interna do próprio âmbito de trabalho, que se compõe de diversas casas de albergamento de jovens.

Nos dois grupos fica evidente, logo na fase inicial da discussão, uma demarcação de fronteira entre a assistência social a jovens (KJH) e a assistência psiquiátrica a jovens (KJP): os dois âmbitos são descritos como sendo contrapostos um ao outro ("Com a psiquiatria? Na organização?" - grupo Montanha, 1. 12-14; "A pergunta se refere a que âmbito, entre os psiquiátricos e nós pedagógicos?" - grupo Ponte, 1. 11). No que segue da discussão ficam evidentes diferenças entre os dois grupos no tocante à modelagem das passagens na cooperação entre a assistência social e a assistência psiquiátrica.

\section{Grupo "Montanha", 1. 41-58}

P1: [...] e acontece muita coisa aqui antes de a gente de fato dizer que

I: $\mathrm{Hm}$.

P1: vamos experimentar com a psiquiatria. Não é?

I:

P10:

I Hm.

P1: (3) E portanto essa é minha experiência; é que nós assim somos no momento quatro colegas (.) e então as opiniões são muito diferentes se a gente, hm, quanto tempo a gente experimenta com uma criança com recursos pedagógicos e quando é chegado o ponto quando uma criança, eh, assim não dá mais prá segurar e quando 
a gente se pergunta se de algum modo a gente pode, hm, considerar de alguma maneira a ajuda da psiquiatria, não é?

P9: Sim, e o contrário também: algumas crianças vêm da psiquiatria para nossos grupos, não é. Portanto (.) esses casos também ainda existem.

Na proposição de P1 (1. 41-45), já está indicado que a própria organização ("aqui") e a psiquiatria se confrontam com relação a suas respectivas competências. A competência pedagógica é mantida durante muito tempo ("acontece muita coisa aqui") antes da assistência psiquiátrica a jovens ser acionada. Na fala é enfatizada uma sucessão espacial e temporal. Ao mesmo tempo fica expresso que a ajuda da assistência psiquiátrica a jovens é vista com uma certa reserva ("vamos experimentar com a psiquiatria"). Manifestamente é necessária uma decisão explícita numa situação aguda para efetivamente ("de fato") acionar a psiquiatria. A assistência psiquiátrica a jovens, portanto, está sobretudo num horizonte negativo.

$\mathrm{Na}$ sequência da discussão, P1 elabora isso. Na perspectiva dos colaboradores da assistência social a crianças e jovens a troca para a assistência psiquiátrica a jovens só é cogitada quando uma fronteira na forma de um "ponto final pedagógico" tiver sido atingida. Ou seja, quando o sistema próprio de assistência já tiver sido esgotado ("quanto tempo a gente experimenta com uma criança com recursos pedagógicos e quando é chegado o ponto quando uma criança assim não dá mais prá segurar e quando a gente se pergunta se de algum modo a gente pode, hm, considerar de alguma maneira a ajuda da psiquiatria"). Quando a competência e o conhecimento específico próprios chegam ao limite, isso precisa ser negociado na equipe pedagógica ("as opiniões são muito diferentes"). A negociação se refere ao momento em que uma transposição da fronteira em direção à assistência psiquiátrica a jovens deve ser iniciada. A identificação desse momento ocorre mediante uma adscrição à criança ("não dá mais prá segurar"). A constatação de que "não dá mais prá segurar" se refere no caso à organização de assistência social e vem acompanhada da demarcação de uma fronteira pedagógica. A mudança de competência é negociada indiretamente dentro da equipe de assistência social através da determinação do momento da "insustentabilidade" e implica numa troca de domicílio. Com isso fica clara a concepção de uma sequência, de uma alternativa ou...ou, de uma exclusão recíproca das competências da assistência social e da assistência psiquiátrica a jovens. De acordo com isso, no grupo "Montanha" a cooperação entre os sistemas é documentada pela entrega ou transferência de competência ("o contrário também: algumas crianças vêm da psiquiatria para nossos grupos”). 
A ajuda que se pode esperar da assistência psiquiátrica é explicitada de modo difuso e vista com ceticismo. Trata-se de uma ajuda "de algum modo", uma solução de emergência ou aparente, que é levada em consideração porque faltam outras possibilidades de ajuda ou ação. Com isso a equipe atesta que ela coloca os seus próprios limites em sua atribuição como organização pedagógica, e os define tão amplos como possível; por outro lado, fica claro que a demarcação de fronteira não é unívoca, já que existem diferentes avaliações sobre a "sustentabilidade pedagógica" de casos individuais que primeiro precisam ser ponderadas através de discursos. As demarcações de fronteira de cada um seguem difusas. Ademais, as possibilidades pedagógicas de ação são relativizadas em relação à decisão em favor de uma troca de sistema de assistência, o que se expressa pela expressão da "experimentação": a ajuda da assistência psiquiátrica a jovens é descrita como "de algum modo" - como prestação difusa de ajuda, que de parte dos colaboradores da assistência social para crianças e jovens não parece estar relacionada nem a expectativas nem a efeitos concretos. Por conseguinte, a respectiva competência dos dois sistemas de assistência não é determinada com base nas respectivas possibilidades claramente definidas de atuação, mas está à disposição de negociações internas à equipe de assistência social em casos individuais e de emergência. Com isso estão documentadas, por um lado, uma orientação voltada a processos coletivos de comunicação e tomada de decisão e, por outro, formas de articulação da autoafirmação e de competência pedagógicas na medida em que as fronteiras para com a psiquiatria de jovens são projetadas como definitivas e as transposições de fronteiras como sendo exceções.

Grupo "Ponte", 1. 709-731

P5: $\quad L_{-}$Hm. E também é um resultado de nosso trabalho não apresentar a clínica como um instrumento dissuasivo I:

P4:

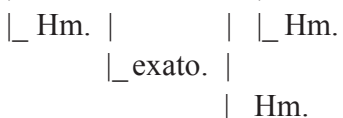

I: Hm.

P5: mas como uma oportunidade para se organizar, se reencontrar e, ao fim e ao cabo, você tem a certeza de, depois, poder continuar aqui conosco ali onde, onde você em algum momento parou [...] portanto, com outra proposta; não é um castigo e não é um afastamento, mas é uma (.) situação de crise que é controlada e depois, tão logo possível, segue (.)

P4: _ de volta ao grupo

P5: $\quad$ L_de volta ao grupo e o trabalho segue com outras coisas onde havia parado antes. 
No grupo "Ponte" fica igualmente claro que os dois grupos se confrontam; mas ao mesmo tempo está aqui documentada uma outra relação da assistência social para com a assistência psiquiátrica. Tendencialmente a assistência psiquiátrica é vista positivamente nessa organização. Através da formulação escolhida fica expresso que esta tendência positiva na avaliação da assistência psiquiátrica está relacionada a um processo ativamente concebido e conscientemente conduzido ("um resultado de nosso trabalho"). A atribuição de papéis à assistência psiquiátrica dentro do contexto do próprio trabalho é feita conscientemente e realizada de forma ativa pelos colaboradores da assistência social, e é, com isso, resultado e sucesso da própria atividade definidora. Os colaboradores da organização se distanciam da imagem negativa generalizada da assistência psiquiátrica (psiquiatria como castigo, um afastamento) ao definirem eles próprios as atribuições da assistência psiquiátrica: a assistência psiquiátrica é apresentada como uma possibilidade útil para as respectivas pessoas jovens (“como uma oportunidade para se organizar, se reencontrar"). ${ }^{4}$ Esta postura com relação à assistência psiquiátrica também é verbalmente transmitida às crianças e aos jovens em questão, o que é revelado pelo pronome ("você").

Aqui se traça uma diferenciação clara entre os âmbitos de competência dos dois sistemas ("situação de crise", "com outra proposta"), e a competência da assistência psiquiátrica é limitada à situação de crise ("se organizar, se reencontrar"). A própria organização de assistência social fixa em que âmbito a assistência psiquiátrica pode se tornar ativa no contexto de sua atividade e define esse marco como sendo apoio em situação aguda de crise. Todas as "outras coisas" são localizadas na esfera de atribuições da organização de assistência social. O conhecimento especializado da psiquiatria de jovens, referida a uma intervenção aguda na crise, não é questionada, como também não é o próprio saber especializado. Simplesmente é constatada a faticidade das respectivas competências. Se bem é verdade que não é concretizado o que está sendo entendido por "situação de crise" ou "outra proposta", revelase uma clara atribuição de competências ao longo de diferentes âmbitos de responsabilidades. Implicitamente se expressa assim quando o saber específico próprio e, com ele, a competência chega ao limite: em situações de crise. As fronteiras também nesse caso são traçadas pelos colaboradores da organização

4 Em diversas outras passagens da discussão em grupo se revela que observações críticas com relação à assistência psiquiátrica a jovens não conseguem se impor no discurso. Processos de negociação e ponderação por parte das pedagogas e dos pedagogos em relação às vantagens e desvantagens de uma vinculação a clínicas psiquiátricas são sinalizados, mas não são admitidos no grupo. 
ao definirem a situação como sendo "de crise"; na comparação com o grupo "Montanha", a crise no entanto não é referida à criança ou ao adolescente. Coerentemente, também não é repassada toda a competência relativa à pessoa jovem à assistência psiquiátrica, mas somente uma competência parcial que se refere à situação de crise, para cujo tratamento se valem dos conhecimentos específicos da psiquiatria de jovens. A competência da assistência psiquiátrica é assim claramente delimitada a um âmbito da atividade (ajuda em situações de crise) que a assistência social a crianças e jovens não define como seu próprio e que ela também não cobre.

Esta diferença nas competências não leva a uma exclusão recíproca do outro sistema de assistência do âmbito de competências próprias. Ao contrário, na perspectiva da assistência social a crianças e jovens, os sistemas de assistência se encontram em uma relação complementar. A permanência na clínica psiquiátrica é definida como uma possibilidade adequada para o tratamento de crises e como interrupção necessária, temporalmente limitada, da permanência no grupo. Não é definida como fim da assistência pedagógica, mas, ao contrário, é ela que permite em seguida uma retomada e continuidade do trabalho pedagógico ("de volta ao grupo e o trabalho segue").

Assim se revela uma relação de utilidade face à assistência psiquiátrica, de que a assistência social faz uso no âmbito concreto de suas competências em situações de crise.

Resumindo pode-se constatar que nas discussões dos grupos "Montanha" e "Ponte" são documentados processos distintos de tratamento modelagem das fronteiras profissionais. No grupo "Montanha" tem-se a pretensão de estender ao máximo a competência pedagógica e de retardar o máximo possível o momento da passagem para a assistência psiquiátrica. A assistência psiquiátrica é vista aqui como o último recurso e sua ajuda só é cogitada quando as medidas pedagógicas tiverem sido esgotadas. A passagem para o sistema de assistência psiquiátrica é vista como uma entrega total e definitiva de competências; nessa passagem, a demarcação de fronteiras entre os dois sistemas aparece como rigorosa e a fronteira é tida como impermeável.

No grupo "Ponte", ao contrário, se evidencia uma relação de utilidade para com a assistência psiquiátrica, que é relacionada a uma distribuição específica de competências entre os dois sistemas. Através desta divisão de tarefas são demarcadas as competências e as não-competências de cada sistema e, com isso, também são demarcadas fronteiras. Mas os transbordos de fronteira não são associados a uma passagem completa; são vistos como uma mudança temporalmente limitada de competência - referida a uma tarefa específica. A competência pedagógica própria não é encerrada com a passagem 
a outro sistema. Assim a fronteira entre os dois sistemas é concebida como permeável e elástica, possibilitando uma concomitância de competências.

\section{Serviço Social como tratamento de fronteira no contexto da pesquisa sobre profissões}

A pesquisa sobre profissões no Serviço Social se refere a três ênfases: em primeiro lugar, às especificidades da profissão, colocando em relevo seus aspectos sociais; segundo, pesquisas sobre a profissionalização como processo de consolidação do Serviço Social como profissão; e, terceiro, discursos sobre profissionalismo, ou seja, sobre o fato de o Serviço Social atuar em situações complexas, por vezes também paradoxais e ambivalentes (cf. Dewe e Otto, 2011, p. 1131). Se no final desse artigo discutimos o Serviço Social como tratamento de fronteira, então nos referimos à terceira ênfase da pesquisa sobre profissões.

Os resultados preliminares de dois grupos de discussão de nossa pesquisa aqui apresentados podem primeiramente ser focalizados nas seguintes perguntas heurísticas: quando, onde, como, para que e até que ponto são revelados processos de legitimação da competência e do conhecimento especializado sociopedagógicos? A pergunta pelo quando da legitimação de competência e conhecimento especializado, na qual, ao lado da questão do como, nos concentramos aqui por razões de espaço, não se coloca no cotidiano da Pedagogia Social, exceto se forem criados espaços de reflexão específicos com esta finalidade, como no caso da supervisão: aqui eles até certo ponto são considerados condição "normal" para o agir profissional. Mas quando surgem crises com crianças e jovens que não sejam mais passíveis de tratamento pela pedagogia, então aquele saber conjuntivo (e experimental) torna-se necessário: primeiro, um saber sobre capacidades e possibilidades profissionais do Serviço Social; segundo, um saber sobre as zonas fronteiriças ainda passíveis de tratamento pedagogicamente; e, terceiro, um saber relativo à modelagem profissional da passagem entre os sistemas. É necessário saber quando e onde outros são indispensáveis e é necessário saber o que o outro é capaz de fazer. Essas formas de saber não são apenas incluídas em interpretações normativas de problemas e nas relações tensionadas da profissão, mas elas também são reproduzidas nas respectivas práticas. Ao mesmo tempo essas formas sociopedagógicas de saber se esquivam tanto de uma padronização e generalização profissionais como formam também a base da capacidade profissional de agir e são recursos centrais na solução de problemas sociopedagógicos (cf. Dewe, 2009, p. 91-92). No contexto de expectativas sociais de normalização e efetividade com relação ao Serviço 
Social, as práticas de legitimação do conhecimento profissional especializado e das competências tornam-se existenciais e necessitam uma reflexividade correspondente caso se queira reivindicar esta profissionalidade e competência (cf. Dewe e Otto, 2011, p. 1150).

Os processos de tratamento de fronteira entre a assistência social e a assistência psiquiátrica a crianças e jovens estão decisivamente influenciados e ao mesmo tempo são reproduzidos pelas hierarquias entre as profissões e organizações (cf. Bütow, 2012a; Wehner, 2002). No tocante à questão sobre como o tratamento de fronteira se manifesta, nos dois grupos puderam ser reconstruídas diferenças correspondentes, que podem ser creditadas às diferenças entre as respectivas filosofias organizacionais e às autocompreensões dos profissionais. ${ }^{5}$ No grupo "Montanha", processos coletivos de busca de acordos assim como a manutenção de fronteiras claras com relação à psiquiatria são centrais. Historicamente a organização surgiu nos anos 1970 a partir da crítica radical à educação tradicional em lares e à psiquiatria, e ainda se mantém fiel a esta autocompreensão (cf. Bütow e Maurer, 2013, p. 267-268). O grupo "Ponte" tem sua origem numa grande e tradicional organização ligada ao apoio a jovens, que desenvolveu muitas suborganizações e por conseguinte muitas estruturas internas e externas de cooperação e de distribuição de competências. Portanto, as diferenças no tratamento de fronteira dos dois grupos podem ser interpretadas no contexto das organizações como "memória" da experiência no agir profissional, pois a práxis realizada nelas e através delas repousa sobre decisões -tomadas outrora e sempre de novo renovadas- sobre a organização do trabalho, modos de processamento das tarefas etc.; mas também com base na avaliação mais ou menos consciente e formalizada das experiências feitas com a práxis resultante das decisões referidas. Essas experiências foram representadas e reivindicadas como válidas nas discussões em grupo e puderam assim ser interpretadas através da reconstrução documental da práxis de constituição de "espaços conjuntivos de experiência". As organizações do Serviço Social são consideradas como resultado de processos profissionais e disciplinares de interpretação e classificação com relação a situações problemáticas, que vêm acompanhadas de uma reivindicação (ou atribuição) de competência. A legitimidade de organizações e, com isso, da atuação profissional, no contexto da tríade de estoques regulativos, normativos e de saberes (cf. Powel, 2009), resulta da atribuição gradativa em e entre organizações e suas pessoas de referência na medida em que os conteúdos (institucionalizados) das organizações são

\footnotetext{
5 Por limitações do espaço estas análises não podem ser apresentadas aqui.
} 
reconhecidos. "Legitimidade significa a adscrição que ocorre no ator que julga e não é primariamente um atributo de instituições. A efetivação de expectativas sociais em estruturas e práticas organizacionais pode produzir legitimidade, mas não necessita fazê-lo obrigatoriamente, uma vez que a legitimidade depende apenas da avaliação dos grupos relevantes de referência no ambiente da organização" (Koch, 2009, p. 126). "Legitimação", por conseguinte, designa aqueles processos de produção, articulação e reconhecimento de legitimidade. Por conseguinte, os processos de tratamento de fronteira na tensa relação entre o serviço social e a psiquiatria de crianças e jovens aqui analisados sempre são também processos nos quais hierarquias estabelecidas são reproduzidas, mas também podem ser deslocadas. Nos dois grupos apresentados isso ocorre de modo distinto: enquanto o grupo "Montanha", através de reivindicações de autonomia, demarcações de fronteiras e questionamento do conhecimento especializado da psiquiatria de crianças e jovens, tenta se reafirmar frente ao "outro" até chegar aos limites da Pedagogia Social, o grupo "Ponte" não reflete hierarquias explicitamente. Ao contrário: a ficção de uma cooperação "entre iguais" modela um marco coletivo, ao passo que uma reflexão crítica não consegue se estabelecer internamente.

Porém, a partir da situação efetiva de que praticamente não existe uma responsabilização conjunta pelos casos entre profissionais da assistência social (KJH) e da assistência psiquiátrica a crianças e jovens (KJP) (cf. Fegert e Schrapper, 2005; Wehner, 2002), persiste para o público-alvo das organizações de assistência aos jovens o risco de um "jogo de empurra-empurra", que pode resultar numa perpetuação de situações problemáticas (cf. Bütow e Maurer, 2013, p. 268). Por isso é necessário a perspectiva dos destinatários no centro da modelagem profissional de fronteiras entre os diferentes sistemas de assistência. Assim, "objetos de fronteira", isto é, de negociações sobre atribuições e saberes especializados específicos ou conjuntos, podem transformar-se em "sujeitos fronteiriços".

Com relação à sequência da presente análise: os dois modos de tratamento de fronteira esboçados e apresentados aqui, como de resto toda tipificação, estão sujeitos a uma hipostasia, a saber, de que coisas e processos sejam percebidos como incluídos, excluídos, classificados, e assim se tornem refratários a reflexões críticas e a novas análises (cf. Hörster, 2013, p. 17). Por isso gostaríamos de finalizar enfatizando que a imagem do tratamento de fronteira é um princípio metodológico que exige abertura e reflexividade, não tendo portanto como finalidade a elaboração de uma tipologia; ela pretende conduzir a atenção para reconstruções a respeito do como da atuação da Pedagogia Social. 


\section{Referências}

BAADER, M. Erziehungswissenschaft zwischen disziplinären Grenzen, Grenzüberschreitungen und Entgrenzungen. In: H.-R. Müller; S. Bohne; W. Thole (Orgs.). Erziehungswissenschaftliche Grenzgänge: Markierungen und Vermessungen - Beiträge zum 23. Kongress der Deutschen Gesellschaft für Erziehungswissenschaft. Opladen: Barbara Budrich, 2013. p. 61-80.

BAUER, P. Institutionelle Netzwerke steuern und managen: Einführende Überlegungen. In: P. Bauer; U. Otto (Orgs.). Mit Netzwerken professionell zusammenarbeiten: Institutionelle Netzwerke in Steuerungs- und Kooperationsprojekten. Tübingen: Deutsche Gesellschaft für Verhaltenstherapie, 2005. p. 11-54.

BOHNSACK, R. Rekonstruktive Sozialforschung: Einführung in Methodologie und Praxis qualitativer Forschung. 2. ed. Opladen: Leske + Budrich, 1993.

BOHNSACK, R. Dokumentarische Methode. In: R. Hitzler; A. Honer (Orgs.). Sozialwissenschaftliche Hermeneutik. Opladen: UTB, 1997. p. 191-211.

BÖLLERT, K. Grenzenlose Soziale Arbeit: Soziale Arbeit als Grenzgängerin? In: H.-R. Müller; S. Bohne; W. Thole (Orgs.). Erziehungswissenschaftliche Grenzgänge: Markierungen und Vermessungen - Beiträge zum 23. Kongress der Deutschen Gesellschaft für Erziehungswissenschaft. Opladen: Barbara Budrich, 2013. p. 197-218.

BOMMES, M.; TACKE, V. Netzwerke in der funktional differenzierten Gesellschaft. Wiesbaden: VS Verlag, 2011.

BÜTOW, B. Grenzen der Sozialpädagogik: Spannungszonen der Kooperation zwischen Kinder- und Jugendhilfe und Kinder- und Jugendpsychiatrie. Soziale Arbeit, v. 61, n. 12, p. 454-461, 2012a.

BÜTOW, B. Cooperation as border-work: the example of Social Work praxes between youth welfare services and youth psychiatry. Social Work \& Society, v. 10, n. 2, 2012b. <www.socwork.net/sws/article/view/332/669>.

BÜTOW, B.; MAURER, S. Zur Legitimierung sozialpädagogischer Zuständigkeit in Spannungszonen der Kooperation: ein DFG-Projekt zur Analyse komplexer Prozesse im innerdeutschen Ost-West-Vergleich. Soziale Passagen, v. 3, n. 2, p. 299303, 2011.

BÜTOW, B.; MAURER, S. Kontextuelle Herstellungsbedingungen von Partizipation im organisationalen Spannungsfeld von Sozialer Arbeit und Psychiatrie. In: S. M. Weber et al. (Orgs.). Organisation und Partizipation: Beiträge der Kommission Organisationspädagogik. Wiesbaden: Springer VS, 2013. p. 263-272.

DE BOIS, R.; IDE-SCHWARZ, H. Psychiatrie und Jugendhilfe. In: H. U. Otto; H. Thiersch (Orgs.). Handbuch Soziale Arbeit. München: Ernst Reinhardt, 2011. p. 1154-1162.

DEWE, B. Reflexive Sozialarbeit im Spannungsfeld von evidenzbasierter Praxis und demokratischer Rationalität: Plädoyer für die handlungslogische Entfaltung reflexiver Professionalität. In: R. Becker-Lenz et al. (Orgs.). Professionalität in der Sozialen Arbeit: Standpunkte, Kontroversen, Perspektiven. Wiesbaden: VS Verlag, 2009. p. 89-112. 
DEWE, B.; OTTO, H.-U. Professionalität. In: H.-U. Otto; H. Thiersch (Orgs.). Handbuch Soziale Arbeit. München: Ernst Reinhardt, 2011. p. 1143-1153.

DÜRING, D. Kooperation als gelebte Praxis: Steuerungshandeln in Sozialraumteams der Kinder- und Jugendhilfe. Wiesbaden: VS Verlag, 2011.

FEGERT, J. M.; SCHRAPPER, Ch. (Orgs.). Handbuch Jugendhilfe: Jugendpsychiatrie - Interdisziplinäre Kooperation. Weinheim: Juventa, 2004.

FISCHER, J.; KOSELLEK, T. (Orgs.). Netzwerke und Soziale Arbeit: Theorien, Methoden, Anwendungen. Weinheim: Juventa, 2013.

FUHSE, J.; MÜTZEL, S. (Orgs.). Relationale Soziologie: Zur kulturellen Wende der Netzwerkforschung. Wiesbaden: VS Verlag, 2010.

HEITE, C.; KESSL, F.; MAURER, S. (Orgs.). Working at the border (Jubilee Edition Part 2). Social Work \& Society, v. 10, n. 2, 2012. <www.socwork.net/sws/article/view/ $332 / 669>$.

HÖRSTER, R.; KÖNGETER, S.; MÜLLER, B. (Orgs.). Grenzobjekte: Soziale Welten und ihre Übergänge. Wiesbaden: Springer VS, 2013.

KARAFILLIDIS, A. Grenzen und Relationen. In: J. Fuhse; S. Mützel (Orgs.). Relationale Soziologie: Zur kulturellen Wende der Netzwerkforschung. Wiesbaden: VS Verlag, 2010. p. 69-96.

KESSL, F. Soziale Arbeit als Grenzbearbeiterin: Einige grenzanalytische Vergewisserungen. In: S. Neumann; P. Sandermann (Orgs.). Kultur und Bildung: Neue Fluchtpunkte für die sozialpädagogische Forschung? Wiesbaden: VS Verlag, 2009. p. 43-61.

KESSL, F.; MAURER, S. Die ,Sicherheit‘ der Oppositionsposition aufgeben: Kritische Soziale Arbeit als Grenzbearbeitung. Kurswechsel, v. 24, n. 3, p. 91-100, 2009.

KESSL, F.; MAURER, S. Praktiken der Differenzierung als Praktiken der Grenzbearbeitung: Überlegungen zur Bestimmung Sozialer Arbeit als Grenzbearbeiterin. In: F. Kessl; M. Plößer (Orgs.). Differenzierung, Normalisierung, Andersheit: Soziale Arbeit als Arbeit mit den Anderen. Wiesbaden: VS Verlag, 2010. p. 154-169.

$\mathrm{KOCH}, \mathrm{S}$. Die Bausteine neo-institutionalistischer Organisationstheorie: Begriffe und Konzepte im Lauf der Zeit. In: S. Koch; M. Schemmann (Orgs.). Neo-Institutionalismus in der Erziehungswissenschaft: Grundlegende Texte und empirische Studien. Wiesbaden: VS Verlag, 2009. p. 110-131.

MÜlleR, B. Professionalität. In: W. Thole (Org.). Grundriss Soziale Arbeit. Wiesbaden: VS Verlag, 2012. p. 955-974.

MÜLLER, H.-R.; BOHNE, S.; THOLE, W. (Orgs.). Erziehungswissenschaftliche Grenzgänge: Markierungen und Vermessungen - Beiträge zum 23. Kongress der Deutschen Gesellschaft für Erziehungswissenschaft. Opladen: Barbara Budrich, 2013.

POWELL, J. Von schulischer Exklusion zur Inklusion? Eine neo-institutionalistische Analyse sonderpädagogischer Fördersysteme in Deutschland und den USA. In: S. Koch; M. Schemmann (Orgs.). Neo-Institutionalismus in der Erziehungswissenschaft: Grundlegende Texte und empirische Studien. Wiesbaden: VS Verlag, 2009. p. 213-232. 
SIMMEL, G. Lebensanschauung: Vier metaphysische Kapitel. In: G. Fritzi; O. Rammstedt (Orgs.). G. Simmel: Gesamtausgabe. v. 16. Frankfurt am Main: Suhrkamp, 1999. p. 209-425.

THOLE, W. Die Soziale Arbeit: Praxis, Theorie, Forschung und Ausbildung: Versuch einer Standortbestimmung. In: W. Thole (Org.). Grundriss Soziale Arbeit. 4. ed. Wiesbaden: Springer VS, 2012. p. 19-72.

VOGD, W. Rekonstruktive Organisationsforschung: Qualitative Methodologie und theoretische Integration - eine Einführung. Opladen: Barbara Budrich, 2009.

WEBER, S. Netzwerkentwicklung als Lernprozess. In: P. Bauer; U. Otto (Orgs.). Mit Netzwerken professionell zusammenarbeiten. Tübingen: dgvt, 2005. p. 127-180.

WEHNER, K. Kinder- und Jugendhilfe und Psychiatrie. In: W. Schröer; N. Struck; M. Wolff (Orgs.). Handbuch Kinder- und Jugendhilfe. Weinheim: Juventa, 2002. p. $815-830$.

Autora correspondente:

Birgit Bütow

Universität Salzburg, FB Erziehungswissenschaft

Unipark Nonntal, Erzabt-Klotz-Str. 1

5020 Salzburg, Áustria

Recebido em: 23 set. 2013

Aprovado em: 15 out. 2013 